\author{
D) Check for updates \\ Cite this: Org. Biomol. Chem., 2017, \\ 15, 10164 \\ Received 15th November 2017, \\ Accepted 23rd November 2017 \\ DOI: $10.1039 / c 70 b 02795 h$ \\ rsc.li/obc
}

\section{Hydrogen-free reductive amination using iron pentacarbonyl as a reducing agent $\uparrow$}

\author{
Oleg I. Afanasyev, ${ }^{a}$ Dmitry L. Usanov t $^{b}$ and Denis Chusov (D) *a,c
}

\begin{abstract}
We developed solvent-free reductive amination without an external hydrogen source using iron pentacarbonyl as a reducing agent. Neither a catalyst nor any other additives were employed. Various types of substrates are suitable for the reaction, including those with low reactivity, e.g. benzophenone. Among others, the protocol tolerates bromo-, cyano-, benzyloxy-, pyrimidyl and styryl moieties.
\end{abstract}

Selective and step-economical syntheses of complex molecules from starting materials easily available in bulk quantities are highly important from economic and environmental points of view. Such protocols should naturally tolerate a variety of functional groups, so that extra steps of introduction and removal of protective groups can be avoided. Recently, we have developed a series of methods for hydrogen-free reductive addition using carbon monoxide ${ }^{1}$ as a reducing agent. ${ }^{2}$ Starting from aldehydes or ketones, this approach can lead to various classes of compounds, including amines, ${ }^{2 b}$ amides, esters ${ }^{2 e, f}$ pyrrolidines, ${ }^{2 a}$ and nitriles. ${ }^{2 f}$ These transformations are usually highly selective and tolerate the presence of aromatic and aliphatic nitrile groups, ${ }^{2 f}$ esters, ${ }^{2 c}$ phenols,${ }^{2 b}$ carboxybenzyl $(\mathrm{Cbz}){ }^{2 b}$ trifluoroacetamido, ${ }^{2 b} \mathrm{~N}$-benzyl, ${ }^{2 a} \mathrm{O}$-benzyl, ${ }^{2 d}$ aromatic fluoro- ${ }^{2 f}$ chloro ${ }^{2 d}$ and bromo-moieties, ${ }^{2 a}$ cyclopropanes, and even aromatic nitro-groups. ${ }^{2 b}$ Selectivities of these reductive aminations usually appreciably exceed those of standard reductive agents, such as sodium cyanoborohydride. ${ }^{2 b}$ The natural limitation for the employment of these methods in a laboratory is the necessity to use a carbon monoxide cylinder.

\footnotetext{
${ }^{a}$ A.N. Nesmeyanov Institute of Organoelement Compounds of the Russian Academy of Sciences, 119991 Vavilova St 28, Moscow, Russian Federation.

E-mail: chusov@ineos.ac.ru,denis.chusov@gmail.com

${ }^{b}$ Department of Chemistry and Chemical Biology, Harvard University, 12 Oxford Street, Cambridge, MA 02138, USA

${ }^{c}$ Faculty of Science, RUDN University, 6 Miklukho-Maklaya St, Moscow 117198, Russian Federation

$\dagger$ Electronic supplementary information (ESI) available: General procedure, experimental details, IR, HRMS, and NMR spectra. See DOI: 10.1039/ c7ob02795h

¥Current address: Department of Chemistry and Chemical Biology, Harvard University, 12 Oxford Street, Cambridge, MA 02138 (USA).
}

In this context, we sought to develop a homogeneous alternative with $\mathrm{CO}$ in a chemically bound form, e.g. using a metal carbonyl complex as a reductant. ${ }^{3}$ From the points of view of both safety and economy, iron pentacarbonyl seemed to be the best choice since elemental impurities of iron in pharmaceutical products are much less stringently regulated by the corresponding authorities (e.g. FDA) than most other d-metals due to lower intrinsic toxicity of iron. ${ }^{5}$ Moreover production of iron pentacarbonyl exceeds thousands of tons per year and it is the least expensive metal carbonyl available. ${ }^{6}$ Iron tetracarbonyl dihydride is a well-known reducing agent; however, it rapidly decomposes at temperatures above $-20{ }^{\circ} \mathrm{C} .{ }^{7}$ The sodium salt is more stable, but is not commercially available and requires highly basic conditions for the synthesis, which can lead to a narrower substrate scope. ${ }^{4}$ Herein, we describe the protocol for reductive amination which employs nothing but starting materials and iron pentacarbonyl. No solvent or external hydrogen source is needed.

We chose morpholine and $p$-tolylaldehyde as model substrates. In light of the fact that iron pentacarbonyl is a liquid, improvement of the environmental profile of the reaction by the use of solvent-free conditions seemed very interesting. Thus, we heated the reaction components at $90{ }^{\circ} \mathrm{C}$ for 4 hours and did detect formation of product 1a (Table 1, entry 1). The temperature influence was found to be important in the range up to $130{ }^{\circ} \mathrm{C}$ (Table 1, entries 1-3); at higher temperatures no significant yield variability was found (Table 1, entries 3-6). When the amount of the carbonyl was decreased from three to two equivalents, no significant changes were observed (Table 1, entry 3 vs. 8). If the amount of the carbonyl was further decreased, the yield significantly dropped (Table 1, entry 1 vs. 9-11). When the amount of the starting amine (see ESI $\dagger$ ) was increased to three equivalents, the yield increased up to $86 \%$ with reaction time of four hours. Based on the works of Hieber the reaction between amines and iron pentacarbonyl gives complicated clusters ${ }^{8}$ so the mechanism reductive amination with iron pentacarbonyl seems to be complicated. The molybdenum hexacarbonyl showed the potential in the reductive amination as well (Table 1 , entry 3 vs. 12). 
Table 1 Investigation of the effects of the amount of iron pentacarbonyl and temperature on reductive amination

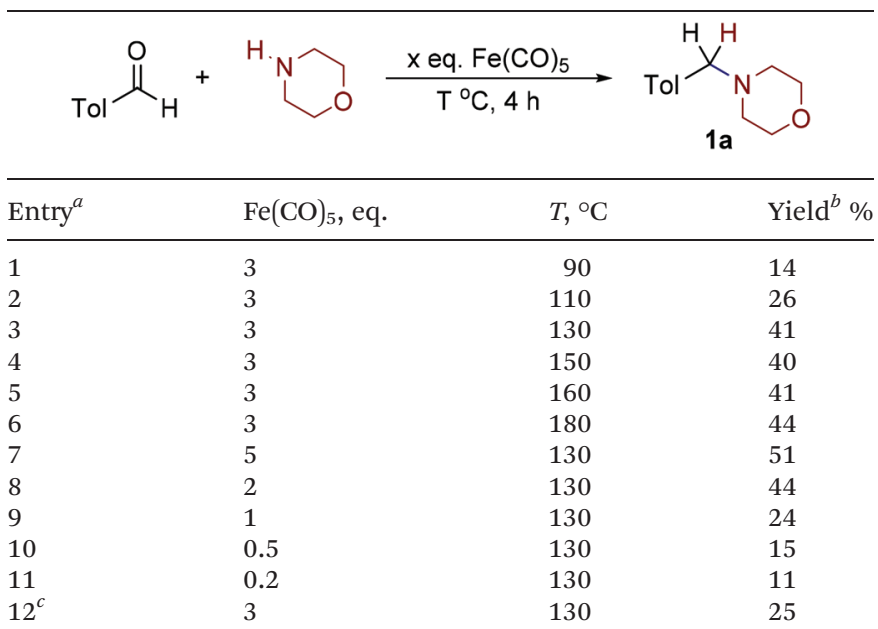

${ }^{a} 0.2 \mathrm{mmol}$ scale. 1.5 eq. of morpholine were used. ${ }^{b}$ Yields were determined by GC. Tol $=p$-methylphenyl. ${ }^{c} \mathrm{Mo}(\mathrm{CO})_{6}$ was used instead of $\mathrm{Fe}(\mathrm{CO})_{5}$.

With these results in hand, we proceeded to investigation of the substrate scope of the developed methodology under the optimized reaction conditions (Fig. 1).

A wide range of aldehydes could be successfully employed, including those containing various functional groups prone to reduction by dihydrogen. For example, benzyloxy moiety (1b), aromatic bromides (1c) and aromatic nitriles (11) can be tolerated. Aliphatic aldehydes are known to undergo self-aldol reaction catalyzed by amines (especially secondary aliphatic amines); ${ }^{9}$ however, under our reaction conditions reductive amination product $\mathbf{1 d}$ was isolated in excellent yield. Whereas ketones are usually much less reactive in reductive amination, our methodology worked well with aliphatic ketones 1e-f. Acetophenone could be converted into product $\mathbf{1 h}$ with isolated yield of $88 \%$. Moreover, even as unreactive ketone as 2 -adamantanone $1 \mathrm{~g}$ successfully furnished the product in $85 \%$ yield. Besides morpholine, other type of tested amines underwent the desired transformation $\mathbf{1 i - k}$ in high yields. The optimum reaction temperature was clearly dependent on the nucleophilicity of the starting amine. For pyrrolidine the reaction proceed well even at room temperature $(\mathbf{1} \mathbf{j}, \mathbf{1} \mathbf{1}, \mathbf{1} \mathbf{n})$. Other type of amines also could react at room temperature, albeit with lower rate. We were surprised to found that even benzophenone could be successfully employed: after 12 hours at $90^{\circ} \mathrm{C}$ product $1 \mathrm{~m}$ was isolated in $69 \%$ yield. The protocol is so mild that we isolated compound $\mathbf{1 n}$ without any side reactions on the styryl moiety.

The scalability and preparative utility of the developed methodology was exemplified on the synthesis of $\mathrm{N}$-adamantylpyrrolidine. Despite the much lower intrinsic reactivity of 2-adamantanone with respect to less sterically challenged substrates, a gram-scale reaction with pyrrolidine proceeded well and furnished product $1 \mathrm{n}$ in $89 \%$ yield without the need for any chromatographic isolation (Scheme 1).
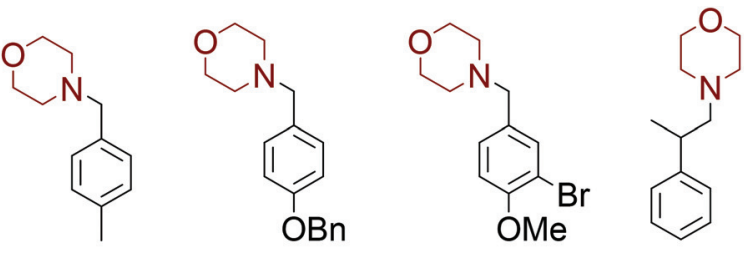

1a, $86 \%$

1b, $70 \%$

1c, $77 \%$

1d, $92 \%$<smiles>c1ccc(CC(Cc2ccccc2)N2CCOCC2)cc1</smiles>

$1 e, 75 \%$

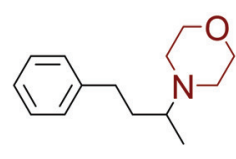

1f, $75 \%$

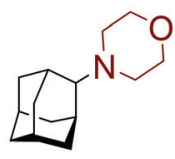

$1 \mathrm{~g}, 85 \%$<smiles>CC(c1ccccc1)N1CCOCC1</smiles>

$1 \mathrm{~h}, 88 \%$

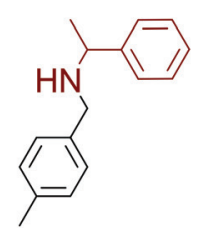

$11,78 \%^{a}$<smiles>Cc1ccc(CN2CCCC2)cc1</smiles>

$1 \mathrm{j}, 85 \%^{b}$

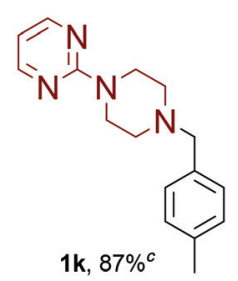

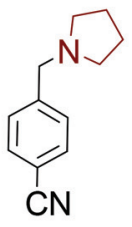

$11,72 \%^{b}$

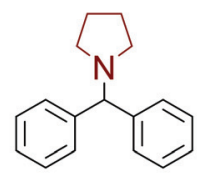

$1 \mathrm{~m}, 69 \%^{d}$

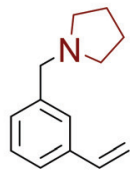

1n, $70 \%^{b}$
Fig. 1 Studies on the substrate scope. Solvent-free conditions. 3 equivalents of $\mathrm{Fe}(\mathrm{CO})_{5}$ and amine were employed. $4 \mathrm{~h}$ at $130^{\circ} \mathrm{C}$. ${ }^{a} 2$ equivalents of amine were employed. $140{ }^{\circ} \mathrm{C}$. ${ }^{b}$ Room temperature. 12 hours. ${ }^{\circ} 140{ }^{\circ} \mathrm{C}$. ${ }^{d} 90{ }^{\circ} \mathrm{C} .12$ hours.

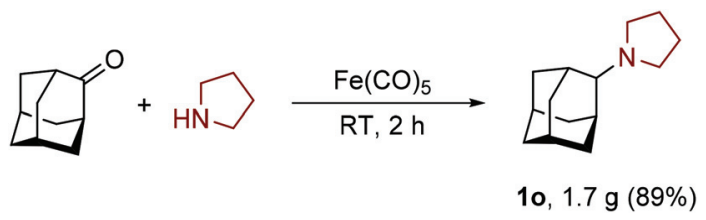

Scheme 1 Scaled-up synthesis of $\mathrm{N}$-adamantyl-pyrrolidine at room temperature.

In conclusion, we have shown that the concept of hydrogenfree reductive amination can be expanded to metal carbonyls as reducing agents, which can lead to the more selective approaches in organic synthesis. The synthetic value of the developed methodology was demonstrated by efficient preparation of a representative range of amines including clean gram-scale synthesis not requiring chromatographic purification. The reaction proceeds well even in case of poorly reactive ketones such as benzophenone. 


\section{Conflicts of interest}

There are no conflicts of interest to declare.

\section{Acknowledgements}

We gratefully thank Professor Terent'ev A. O. and Dr Vil' V. for the inspiring us to work with iron carbonyl. This work was supported by the Russian Foundation for Basic Research (15-0302548). D. C. thanks the Ministry of Education and Science of the Russian Federation (Agreement number 02.a03.21.0008). The contribution of Center for molecule composition studies of INEOS RAS is gratefully acknowledged.

\section{Notes and references}

1 For the recent examples of the state-of-the art applications of carbon monoxide as a reducing agent see: (a) S. E. Denmark, M. Y. S. Ibrahim and A. Ambrosi, ACS Catal., 2017, 7(1), 613; (b) M. A. El-Atawy, F. Ferretti and F. Ragaini, Eur. J. Org. Chem., 2017, (14), 1902; (c) M.-M. Zhu, L. Tao, Q. Zhang, J. Dong, Y.-M. Liu, H.-Y. He and Y. Cao, Green Chem., 2017, 19(16), 3880; (d) A. Ambrosi and S. E. Denmark, Angew. Chem., Int. Ed., 2016, 55(40), 12164; (e) A. Cimino, F. Moscatelli, F. Ferretti, F. Ragaini, S. Germain, J. Hannedouche, E. Schulz, L. Luconi, A. Rossin and G. Giambastiani, New J. Chem., 2016, 40(12), 10285; (f) H.-Q. Li, X. Liu, Q. Zhang, S.-S. Li, Y.-M. Liu, H.-Y. He and Y. Cao, Chem. Commun., 2015, 51, 11217; (g) J. W. Park and Y. K. Chung, ACS Catal., 2015, 5, 4846; (h) F. Ferretti, M. A. EL-Atawy, S. Muto, M. Hagar, E. Gallo and F. Ragaini, Eur. J. Org. Chem., 2015, 5712; (i) S. E. Denmark and Z. D. Matesich, J. Org. Chem., 2014, 79(13), 5970; (j) F. Ferretti, F. Ragaini, R. Lariccia, E. Gallo and S. Cenini, Organometallics, 2010, 29(6), 1465; (k) S. E. Denmark and S. T. Nguyen, Org. Lett., 2009, 11(3), 781; (l) F. Ragaini, F. Ventriglia, M. Hagar, S. Fantauzzi and S. Cenini, Eur. J. Org. Chem., 2009, 2185; (m) F. Ragaini, M. Gasperini, S. Cenini, L. Arnera, A. Caselli, P. Macchi and N. Casati, Chem. - Eur. J., 2009, 15(32), 8064; (n) F. Ragaini, Dalton Trans., 2009, 32, 6251; (o) F. Ragaini, S. Cenini, S. Tollari, G. Tummolillo and R. Beltrami, Organometallics, 1999, 18(5), 928; ( $p$ ) S. Cenini, F. Ragaini, S. Tollari and D. Paone, J. Am. Chem. Soc., 1996, 118(47), 11964.
2 (a) O. I. Afanasyev, A. A. Tsygankov, D. L. Usanov and D. Chusov, Org. Lett., 2016, 18, 5968; (b) O. I. Afanasyev, A. A. Tsygankov, D. L. Usanov, D. S. Perekalin, N. V. Shvydkiy, V. I. Maleev, A. R. Kudinov and D. Chusov, ACS Catal., 2016, 6(3), 2043; (c) N. Z. Yagafarov, P. N. Kolesnikov, D. L. Usanov, V. V. Novikov, Y. V. Nelyubina and D. Chusov, Chem. Commun., 2016, 52(7), 1397; (d) P. N. Kolesnikov, N. Z. Yagafarov, D. L. Usanov, V. I. Maleev and D. Chusov, Org. Lett., 2015, 17(2), 173; (e) P. N. Kolesnikov, D. L. Usanov, E. A. Barablina, V. I. Maleev and D. Chusov, Org. Lett., 2014, 16, 5068; (f) N. Z. Yagafarov, D. L. Usanov, A. P. Moskovets, N. D. Kagramanov, V. I. Maleev and D. Chusov, ChemCatChem, 2015, 7(17), 2590; (g) D. Chusov and B. List, Angew. Chem., Int. Ed., 2014, 53, 5199.

3 For the state-of-the art applications of metal carbonyls as a reducing agent see: (a) F. Zhou, D.-S. Wang, X. Guan and T. G. Driver, Angew. Chem., Int. Ed., 2017, 56(16), 4530; (b) N. Jana, F. Zhou and T. G. Driver, J. Am. Chem. Soc., 2015, 137(21), 6738; (c) F. Zhou, D.-S. Wang and T. G. Driver, Adv. Synth. Catal., 2015, 357(16-17), 3463; (d) B. J. Stokes and T. G. Driver, Eur. J. Org. Chem., 2011, (22), 4071.

4 (a) S. C. Shim, K. T. Huh and W. H. Park, Tetrahedron, 1986, 42(1), 259; (b) S. C. Shim and Y. Watanabe, Bull. Korean Chem. Soc., 1982, 3(2), 76; (c) Y. Watanabe, S. C. Shim, T. Mitsudo, M. Yamashita and Y. Takegami, Bull. Chem. Soc. Jpn., 1976, 49(8), 2302; (d) Y. Watanabe, S. C. Shim, T. Mitsudo, M. Yamashita and Y. Takegami, Bull. Chem. Soc. Jpn., 1976, 49(5), 1378.

5 http://www.fda.gov. US Pharmacopeia general chapter $<231>$. 6 The carbonyls can be purchased from Sigma-aldrich. Fe $(\mathrm{CO})_{5} 231$ USD per $\mathrm{kg}\left(0.23\right.$ USD per g); $\mathrm{Mn}_{2}(\mathrm{CO})_{10} 109$ USD per $50 \mathrm{~g}$ (2.18 USD per $\mathrm{g})$; $\mathrm{Mo}(\mathrm{CO})_{6} 1322$ USD per $500 \mathrm{~g}$ (2.64 USD per g); $\mathrm{Co}_{2}(\mathrm{CO})_{8} 1532$ USD per $500 \mathrm{~g}$ (3.06 USD per g); $\mathrm{W}(\mathrm{CO})_{6} 456$ USD per $100 \mathrm{~g}$ (4.56 USD per g); $\mathrm{Cr}(\mathrm{CO})_{6} 498$ USD per $100 \mathrm{~g}$ (4.98 USD per $\mathrm{g}$ ).

7 (a) P. Krumholz and H. M. A. Stettiner, J. Am. Chem. Soc., 1949, 71(9), 3035; (b) P. Rittmeyer and U. Wietelmann, in Ullmann's Encyclopedia of Industrial Chemistry, Wiley-VCH Verlag GmbH \& Co. KGaA, 2000.

8 W. Hieber and N. Kahlen, Chem. Ber., 1958, 91, 2223.

9 S. Mukherjee, J. W. Yang, S. Hoffmann and B. List, Chem. Rev., 2007, 107(12), 5471. 